\title{
A Study on Developing Designs and the Practical Use of Outdoor Backpacks Equipped with Solar Cells
}

\author{
Park Jinhee
}

Dept. of Clothing \& Textiles, The University of Suwon

\begin{abstract}
'Smart Clothes', which incorporate topnotch digital technology into fashion, are a leading fashion runner in this digital era. The purpose of the study is to first help develop a practical design for outdoor backpacks which are equipped with eco-friendly solar cells that facilitate recharging diverse smart devices during outdoor activities; and, secondly, to offer some practical data from the actual appropriation tests that will be used for manufacturing such products. This trial study finds out how to conjoin some practical IT devices with fashion items and mainly focusses on designing outdoor backpacks which are loaded with solar cells for recharging electric devices, and, later, experiments on designed backpacks with some smart phones to see how it works. According to the desired purposes of backpacks, all the features can be adjusted and modified such as the kinds of solar cell panels, materials, sizes, positions of attachment, weights, etc. Smart Clothes are highly functional and fashionable items that satisfy both practical and emotional purposes, and are being actively developed to serve consumers. This study proves that Smart Clothes or Smart Wear will have practical uses for outdoor activities and will possibly lead our smart lifestyles.
\end{abstract}

Key words : backpack, outdoor wear, smart clothing, solar cell

\section{Introduction}

In this age of high-tech science of the twenty first century, digitized clothing coupling fashion with science has become a significant trend in the apparel industry. So called 'Smart Clothes', hiring topnotch digital technology into fashion, are a leading fashion runner in this digital era.
They are making more and more progress developing new materials with new technology shaping a new realm of smart clothing market. Hence, apparel manufacturers in the whole world are competing for developing and marketing smart clothes (J. Lee, 2008). Fashion fabric products for clothing across the world nowadays are inclined to be of high quality having more diversity. The life style change, due to the enlarged leisure hours and the aging of the society,

Corresponding author: Park Jinhee, Tel. +82-10-8970-4677, Fax. +82-2-821-4677

E-mail: jinnyangel2000@hanmail.net 
Park Jinhee / A Study on Developing Designs and Practical Use of Outdoor Backpacks Equipped with Solar Cells

caused people to buy more of highly functional and sports/casual clothes rather than formal dress. The trend of pursuing high quality, high functionality, light weight and diversity is quite universal and the demand for high-quality and highly-functional fabric is rapidly increasing. Futhermore, with the elevated standard of living, people tend to be more interested in eco-friendly products. Thus, more and more studies in fabric industry are now focused on developing fabric materials environmentally friendly both while being used and after being abolished (Korea Federation of Textile Industries, 2011).

We are living in the information technology age or digital age. This era has a remarkable characteristic which is a mobile age. Since we go everywhere with digital devices, they get smaller enough to be portable and handy and they are evolving to be wearable. Smart Clothes, combining diverse digital devices and functions with clothes at the same time maintaining the unique characteristics as clothing, are a starting point to enter into a wearable age (Hyunseung Cho et al., 2005). Smart Clothes are distinguished from conventional clothes in that digital devices are not only just attached to clothes but they get tiny enough and go built-in and they are smart to function in favor of the wearer (H. Lee, 2008).

As smart clothes are getting commonplace, more studies and surveys, for example to find out target consumers and to estimate demand, on smart clothes are necessary as done on conventional clothes (Hakyung Cho, Kim, \& Lee, 2010). A study, however, on the preference test for smart clothes suggests that those who are sensitive to fashion trends showed more preference for smart clothes rather than those who are considered to be more interested in technology did. It means that smart clothes are better understood in terms of highly trendy fashion items equipped with functional parts (Kang \& Jin, 2007).

Meanwhile, IT devices have kept renovating in order to satisfy the users' needs to go smarter, compacter, and lighter. They are now evolving into fashion items that can be comfortably worn. Thus, there should be a proper attention to the possible market share of 'smart outdoor wear' loaded with fancy IT gadgets still pertaining fashionable fitness other than just conventional outdoor wear market.

Korea has a strong IT industry and is highly expected to witness an outstanding growth in smart industry. Besides, more and more people take to the road on weekends and outdoor activities are becoming more common, which means we may face more problems concerning recharging our digital devices outside home. In this regards, Solar Clothes using solar energy are aggressively being studied. Solar energy itself is also attracting researchers who are concerned about getting ready for the upcoming age of energy crisis. Solar energy as a clean energy, coupled with the need of ubiquitous age, is already being actively researched in some developed countries. Studies on Solar Clothes are now news in Korea, yet $R$ \& Ds in this area are ungently needed (Jeong, 2010). Except that, it is lacking of research on fashion combined with solar cells. Now products in development of solar cells are mostly of foreign products, for example, solar panel backpack of $\mathrm{RLX}$, which is hard material type like most of solar cells. When it combined with flexible clothing and fashion accessory items, it stands out to be heterogeneity. And when Solar cells is not required on day-to-day activities in the city, with the appearance of solar cells, it represented inappropriate appearance and 
moreover, it does not meet consumers' desire to buy. Therefore, this study pursues to apply the flexible solar cell suitable to fashion products, to develop design which can satisfy aesthetic aspects as well as functional aspects in everyday life.

The purpose of the study is first to help develop a practical design of outdoor backpacks equipped with eco-friendly solar cells to facilitate recharging diverse smart devices during outdoor activities, and secondly by actual appropriation test to offer some practical data to be used in manufacturing such products.

\section{Methods and Procedures}

The study is a trial to find out how to conjoin some practical IT devices with fashion items and is mainly focussed on designing outdoor backpacks loaded with solar cells for recharging electric devices and later experimenting on a such designed backpack with some smart phones to see how it works. The solar cells used in this study are outdoor foldout sunlight panels and they are connected to USB recharging sockets for smart phones. Backpacks are designed to be used for both town and outdoor and of course to be able to accept solar cells.

\section{Applied Solar Cell Panel}

When smart clothing has all usefulness, comfort, safety, durability, ease of management, esthetic for clothing, it can be accepted as products of daily life (G. Cho \& Cho, 2007). Since it should be carried in outdoor activities, weights and flexibility are to be considered to select a thin and flexible film type solar cell.
Plus, high durability is also considered in case it might be scratched by any things such as branches or fallen to the ground and trod etc. Figure 1 illustrates the features of the solar cells applied to the study.

\section{Designs of the Town/Outdoor Backpack, and the Solar Cell Panel}

Selecting backpack design, the result of the study by Jeong (2012). was considered in which $74 \%$ of the subjects answered that they think of both fashion and function in choosing solar clothes. Current outdoor wear market has a trend for things both town and outdoor (casual outdoor). Therefore, the backpack designed for both town and outdoor was selected for this study. Flap part of the backpack can be rolled up when backpacking, walking or resting the back on a rock to ease recharging smart phones.

The size of the cell panel when fully unfolded is adjusted to the size of the front of the backpack. The cell panel is folded in 5 layers. Recharging unit is developed to use a USB connector which is convenient for directly plugging in smart phones.

\section{How to Conjoin Solar Cell Panel to Backpack}

The cell panel is design to be folded and put in the front pocket of the backpack when not in use. The panel is connected to a smart phone through the USB port for a recharge. The backpack is also designed for wearer to easily take out the phone wearing the backpack. 


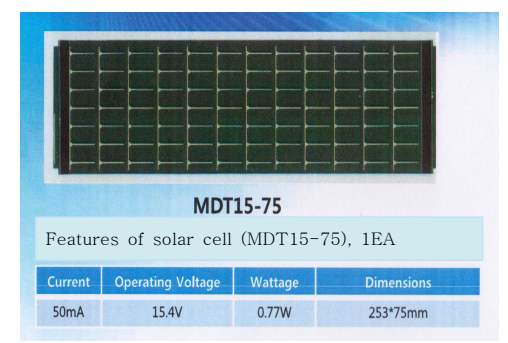

Output Voltage: $15.4 \mathrm{~V}$

Current: $220 \mathrm{mAh}$

Capacity: $3.5 \mathrm{Wh}$

Size: $253 * 75 \mathrm{~mm}$

Figure 1. The Features of the Solar Cells applied, the electric figures are by the Standard Test Conditions (Irradiance $1 \mathrm{KW} / \mathrm{m}^{2}$, Temperature $25^{\circ} \mathrm{C}$, Spectrum $1.5 \mathrm{AM}$, Tolerance $\pm 5 \%$ )
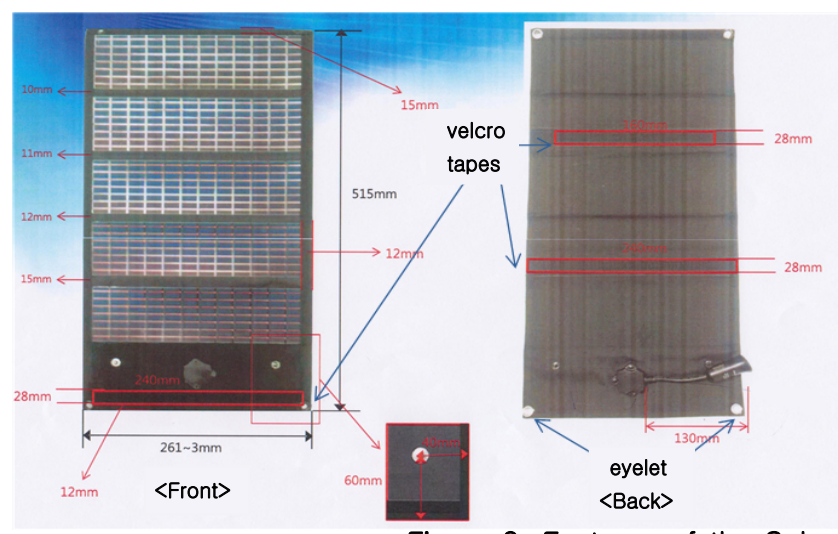

Size (folded) $261 \times 85 \times 26 \mathrm{~mm}$

Size (unfolded) $261 \times 525 \mathrm{~mm}$

Figure 2. Features of the Solar Cell Panel

\section{Recharge Test with different kinds of Smart Phones}

The recharging experiment was carried on different kinds of smart phones with the solar panel altered to hold a USB connector. The amount of being recharged was marked in percentage (\%). For an effective function, the panel was tilted at the entrance angle of between 60 90 degrees. The experiment was done when the sun gives a good illuminance between 10am $\sim 5 \mathrm{pm}$. The subject smart phones were equally adjusted to keep all applications and WIFI being turned off while tested.

\section{The Results and Analysis}

\section{Designs of the Solar Cell Panel}

Considering the normal size of front side of a typical backpack $(30 \times 40 \mathrm{~cm})$, five pieces of panels (each piece $7.5 \mathrm{~cm}$ ) are assembled like Figure 2. This type of panel, originally developed with a plug to be inserted to car cigarette lighter sockets, is modified with a USB connector for smart phones.

The features of the DC recharging connector are Input DC 12-24V, Output 5.0V/MAX 2.1A. Figure 3 shows the illustration of folded solar cell panel and the DC recharging connector. 


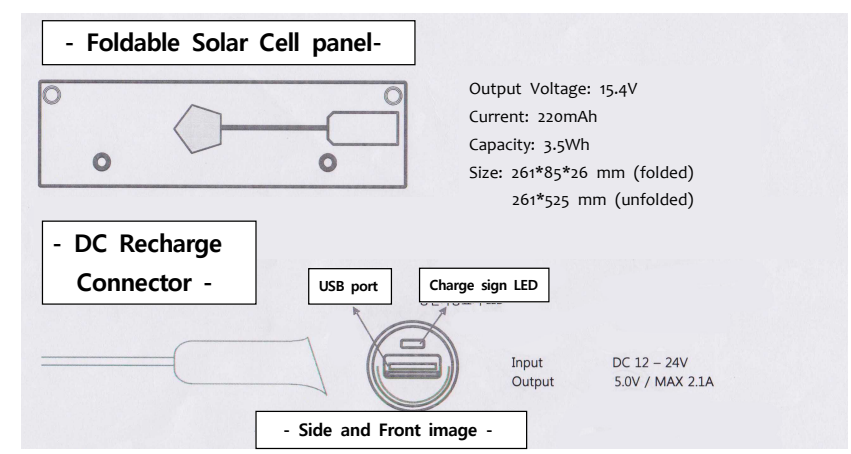

Figure 3. Features of a Folded Panel and DC Recharging Connector with USB port
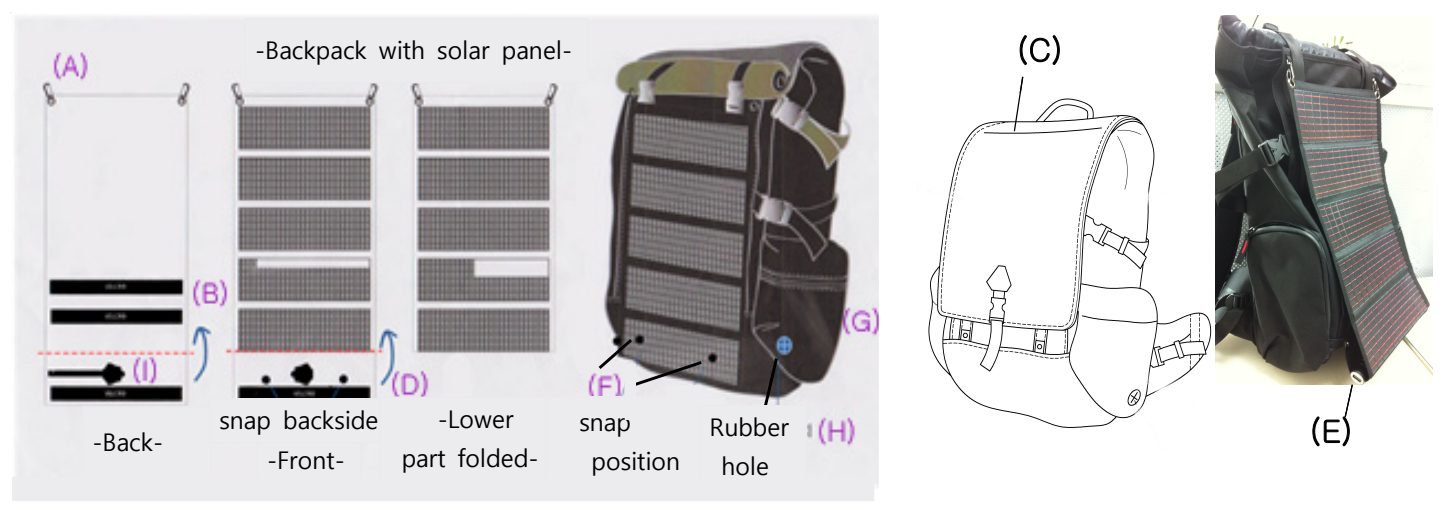

Figure 4. Designs and the Positions of Eyelets, Hooks, and Velcro Tapes

\section{Designs of Backpack for Town/Outdoor, and Solar Cell Panel}

For the top of the solar panel and the top of the backpack, where they are attached and detached frequently, Eyelets \& Snap Hooks (A) are applied to help easily and quickly attach and detach panel and also to assure they are securely attached during outdoor activities. For the center and the bottom of the panel, Velcro tapes (B) are applied so that the panel will stay put to the backpack stably. While in use, the panel is attached to the backpack; when not in use, the panel is folded and kept inside the pocket at the front of the backpack (C). In order to make a beautiful and neat arrangement, the bottom panel with USB connector is designed to be folded backwards; (D) the USB port and the wires are guided underneath and between the backpack and the panel to be minimally exposed; (E) two snap buttons at the bottom of the panel (F) will help the panel securely attached to the backpack. The smart phone is meant to be carried inside the lower pocket $(G)$ at the right side of the backpack (for right-handed people) to easily take it out. At the bottom of the pocket, there's a rubber hole $(H)$ for the wires for recharging or ear sets to go through and in the wires from the hole goes directly to the USB port (I) at the bottom panel; 
Park Jinhee / A Study on Developing Designs and Practical Use of Outdoor Backpacks Equipped with Solar Cells

in this way they will be least exposed.

The materials of the backpack used are 4200 RIPSTOP, 2100 OXFORD, and TAPAULIN. Figure 4 shows the designs and the positions of eyelets, hooks, and velcro tapes. Figure 5 has the way to attach the panel to the backpack.

\section{Convenience of the Backpack with Solar Cell Panel when Outing}

Since the late 1990s, the smart clothing is required to the end user as user-centered design, human-friendly elements such as ease of use and satisfaction began to emerge as a major research project (Hakyung Cho \& Lee, 2008). In daily life and outdoor environments, backpack could be designed to be user-centered design. Figure 6 illustrates when the panel is being used outdoors and when carried inside not in use in daily life.

When the bag is worn, mesh water bottle pocket is inside of the lower left pocket. The right bottom pocket is for the mobile smart phone and it has a rubber hole for the earphone and charging wire to pass through. Inside the bag, it can carry laptop in a laptop pocket and has the buckle for fixing in town use. In addition, it provides multi-purpose pockets to carry the props. At the top of the bag, the handle can hold the bag with hands. To charge a smart phone, equipped with solar cells, after rolling the flaps, the buckle for fixing was mounted in the top of the pocket. Figure 7 illustrates the backpack design system.

The ventilation system provides space between the bag and the ventilation system. The ventilation system has mesh type body which is breathable. When it is worn, it contacts with back part of the user and the cushion pads absorb shock. In the middle of the system, two wires support the space and the horizontal spacing region control the wire distance. It adjusts the distance of the back part of the wearer and the bag, and provides the effect to maintain optimal fit depending on the size of the body. Over time, Lengthen wire control, when the force to pressure on the body weakens, it can move to the other space with equal force and give the same pressure. Figure 8 illustrates the ventilation system of backpack.

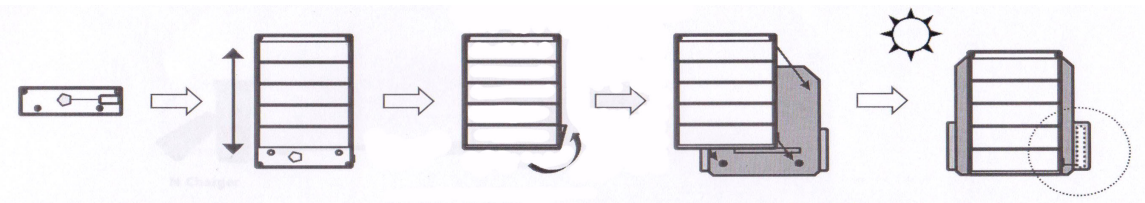

Figure 5. How to Attach the Panel to the Backpack

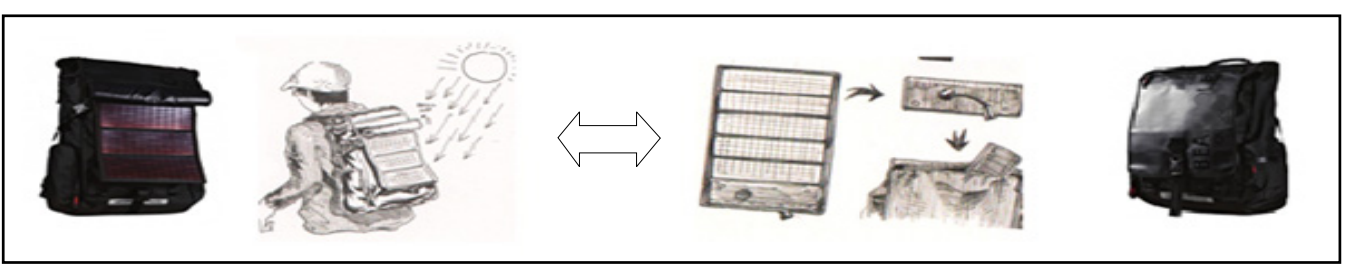

Figure 6. Example of Recharging Smart Phones with Solar Cell Outdoors, Easy Carry When Not in Use

- Backpack for Both Outdoor and Downtown Activities (Beanpole Outdoor, 2012) 

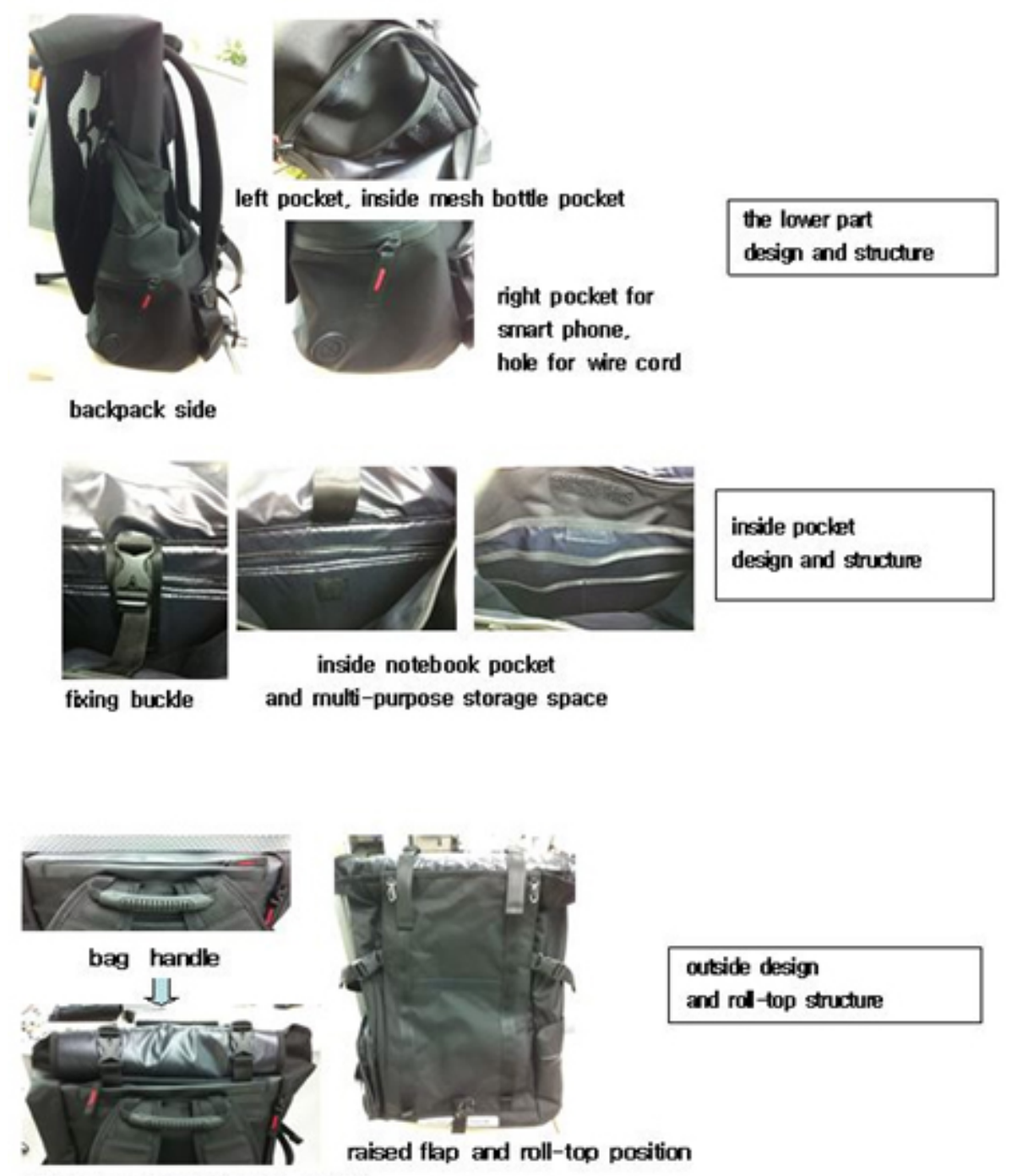

raised flap and roll-top position

flap fxing buckle inside pocket
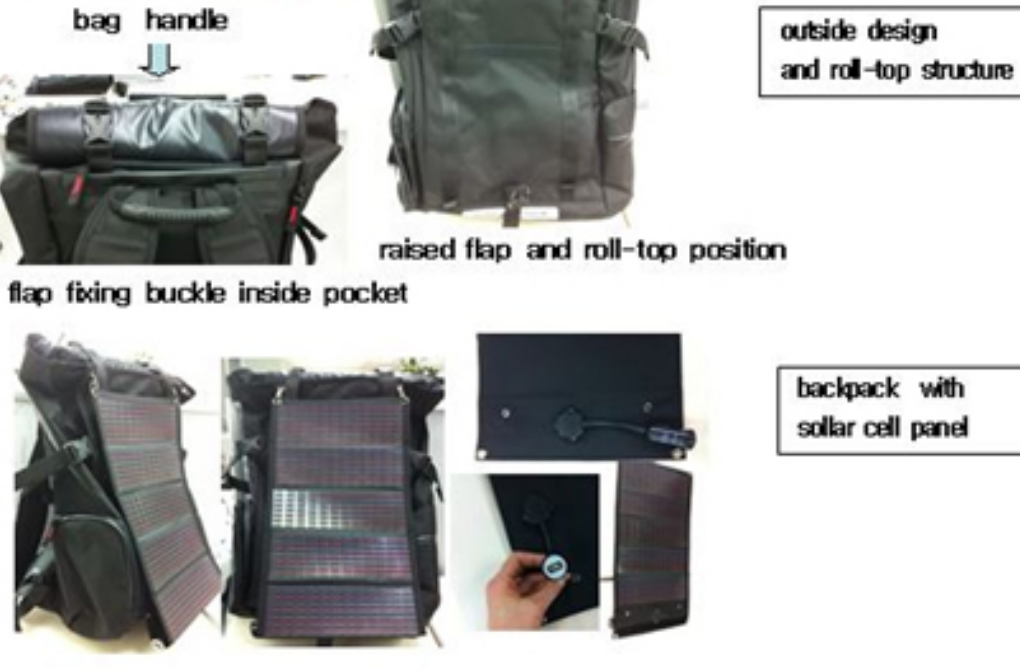

Figure 7. The Backpack Design System 


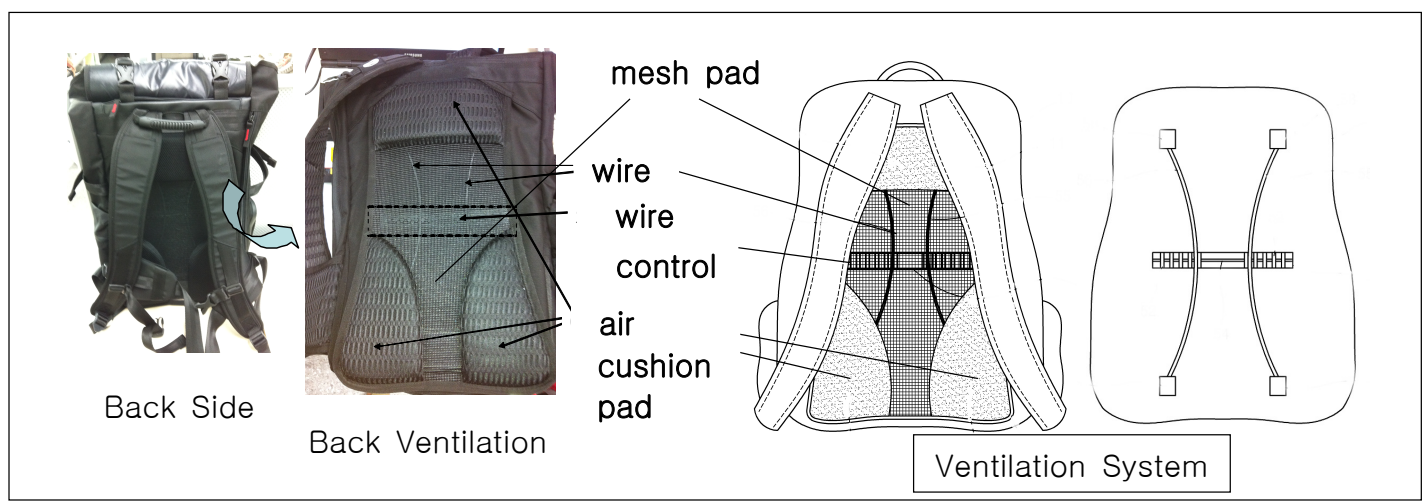

Figure 8. The Ventilation System of Backpack
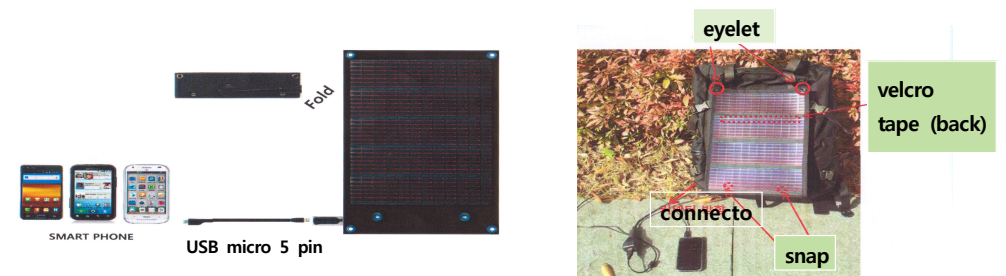

Figure 9. Recharge Test with Different Kinds of Smart Phones

Table 1. Results on Amount of Recharge Using Solar Cell Panel with Modified USB Port Connector

\begin{tabular}{c|c|c|c|c|c}
\hline \hline Devices & $\begin{array}{c}\text { Amount of } \\
\text { Recharge (\%) } \\
\text { Oct. 10 }\end{array}$ & $\begin{array}{c}\text { Amount of } \\
\text { Recharge (\%) } \\
\text { Oct. 11 }\end{array}$ & $\begin{array}{c}\text { Amount of } \\
\text { Recharge (\%) } \\
\text { Oct. 12 }\end{array}$ & $\begin{array}{c}\text { Amount of } \\
\text { Recharge (\%) } \\
\text { Oct. 13 }\end{array}$ & $\begin{array}{c}\text { Average } \\
\text { Amount of } \\
\text { Recharge (\%) }\end{array}$ \\
\hline $\begin{array}{c}\text { Samsung } \\
\text { Galaxy S }\end{array}$ & 61 & 83 & 48 & 75 & 66.8 \\
\hline $\begin{array}{c}\text { Samsung } \\
\text { Galaxy S2 }\end{array}$ & 55 & 75 & 43 & 67 & 60.0 \\
\hline $\begin{array}{c}\text { Samsung } \\
\text { Galaxy Tab 7.0 }\end{array}$ & 17 & 25 & 10 & 18 & 17.5 \\
\hline $\begin{array}{c}\text { LG L BlimuS Black } \\
\text { SKY Vega S }\end{array}$ & 59 & 82 & 49 & 74 & 66.0 \\
\hline Motorola MB 525 & 50 & 83 & 47 & 71 & 62.3 \\
\hline \hline
\end{tabular}

\section{Evaluations on the Amounts of Recharge with different kinds of smart phones}

The recharging experiment was carried on different kinds of smart phones with the solar panel altered to hold a USB connector. The amount of being recharged was marked in percentage (\%). For an effective function, the panel was tilted at the entrance angle of between 60 90 degrees. The experiment was done when the sun gives a good illuminance between 10am $\sim 5 \mathrm{pm}$. The subject smart 
phones were equally adjusted to keep all applications and WIFI being turned off while tested.

For four days of experiment, the average amount of illumination was 69,525 Lux, and the average amount of clouds was 3.8 (Korea Meteorological Administration, 2011); and the average temperature of the batteries was 21.9 $23.3^{\circ} \mathrm{C}$. Under the above conditions, all the smart phones were found to be recharged over $60 \%$ in 5 hours except Galaxy Tab which claims bulky capacity. Therefore, it is assumed that under typical fall weather using the panel for five hours or so with good solar illumination, you can use your portable device to communicate or do whatever you need while you enjoy your outdoor life. You can pack this unweighted panel inside your backpack, and you have a good source of electricity where there's no other electricity provider. It proves that Smart Clothes or Smart Wear will have a practical use in outdoor activities and will positively lead a smart life style. Figure 9 illustrates Recharge test with different kinds of smart phones. Table 1 shows the results of amount of recharge using solar cell panel with smart phones.

\section{Conclusion}

We seem to have noticed a possibility that we, as an individual, can utilize an eco-friendly green energy to make our outdoor life even more enjoyable by solving the recharging problem of our smart devices that we carry all the time with us. Through this study we have seen the designing backpacks and solar cell to conjoin the two to make it smarter enough to recharge our cell phones away from home, and through the actual tests afterward confirmed the designed backpack works fine. The specific results are as follows:

1. Considering the normal size of front side of a typical backpack $(30 \times 40 \mathrm{~cm})$, five pieces of panels (each piece $7.5 \mathrm{~cm}$ ) are assembled to make one panel. The panels, originally developed with a plug to be inserted to car cigarette lighter sockets, are modified with a USB connector for smart phones.

2. Backpack for both town and outdoor purpose is designed and developed to facilitate usage when used to recharge smart phones with solar cells or when not in use as well. More works and trials coupling solar cells and other items are assumed to be highly desirable.

3. According to the desired purposes of backpacks, all the features can be adjusted and modified such as kinds of solar cell panels, materials, sizes, positions of attachment, weights, etc. Smart Clothes or Smart Wear are highly functional and fashionable items satisfying both practical and emotional purposes, and are being actively developed to serve users.

4. For four days of experiment, the average amount of illumination was 69,525 Lux, and the average amount of clouds was 3.8; and the average temperature of the batteries was $21.9 \sim 23.3^{\circ} \mathrm{C}$. Under the above conditions, most of the smart phones were found to be recharged over $60 \%$ in 5 hours. Therefore, it is assumed that you can use your portable devices freely while you still enjoy your outdoor life. It proves that Smart Clothes or Smart Wear will have a practical use in outdoor activities and will possibly lead our smart life style.

\section{References}

Beanpole Outdoor. (2012). Spring catalogue. 
Park Jinhee / A Study on Developing Designs and Practical Use of Outdoor Backpacks Equipped with Solar Cells

Seoul: Cheil Industries Inc.

Cho. G., \& Cho. J. (2007). The development of smart clothing technology for future daily life. Fiber Technology and Industry, 11(2), 111-116.

Cho, H. [Hakyung], Kim, J., \& Lee, J. (2010), A study of directions for development of smart clothing based on the consumer's lifestyle. Koean Journal of the Science of Emotion \& Sensibility, 13(1), 11-20.

Cho, H. [Hakyung], \& Lee, J. (2008). The development of usability evaluation criterion for sensor based smart clothing. Journal of the Korean Society for Clothing Industry, 10(4), 473-478.

Cho, H. [Hyunseung], Kim, Y., Kim, H., Seo, J., Lee, S., Lee, J., \& Whang, E. (2005). A development of the prototypes of smart sportswear for trekking and jogging. Koean Journal of The Science of Emotion \& Sensibility, 8(3), 213-220.

Jeong, Y. (2010). Application method of solar cells for making solar garments. Proceedings of 2010 Winter Conference (pp. 98-99). Iksan: Korean Living Science Association.
Jeong, Y. (2011). Development status of solar garments and a survey on the solar clothing construction. Journal of the Korean Society for Clothing Industry, 13(5), 806-814.

Kang, K., \& Jin, H. (2007). Influences of consumers' fashion innovativeness and technological innovativeness on attitudes and buying intention toward smart clothing. Journal of the Korean Society for Clothing Industry, 9(1), 35-40.

Korea Federation of Textile Industries. (2011). Textile-lT convergence issues report. Seoul: Korea Federation of Textile Industries.

Korea Meteorological Administration. (2011). Retrieved from http://www.kma.go.kr/weather/ observation/data_monthly.jsp

Lee, H. (2008). Study on the design of smart photonic clothing based on inorganic EL technology (Unpublished master's thesis), Yonsei University, Seoul, Korea.

Lee, J. (2008). Development and evaluation of smart jacket with embedded wearable device. Journal of the Korean Society of Clothing and Textiles, 32(3), 395-407.

Received(Nov. 19, 2013)

Revised(Dec. 5, 2013)

Accepted(Dec. 6, 2013) 